NBER WORKING PAPER SERIES

\title{
CONSOLIDATING THE EVIDENCE ON INCOME MOBILITY IN THE WESTERN STATES OF GERMANY AND THE U.S. FROM 1984-2006
}

\author{
Gulgun Bayaz-Ozturk \\ Richard V. Burkhauser \\ Kenneth A. Couch \\ Working Paper 18618 \\ http://www.nber.org/papers/w18618
NATIONAL BUREAU OF ECONOMIC RESEARCH
1050 Massachusetts Avenue
Cambridge, MA 02138
December 2012

We thank Dean Lillard, Richard Hauser, Stephen Jenkins, and participants at the 2011 Cornell Population Center Conference on Comparative International Research for their helpful comments and suggestions. We also thank Tom Rushmer for assistance in production of the manuscript. The views expressed herein are those of the authors and do not necessarily reflect the views of the National Bureau of Economic Research.

NBER working papers are circulated for discussion and comment purposes. They have not been peerreviewed or been subject to the review by the NBER Board of Directors that accompanies official NBER publications.

(C) 2012 by Gulgun Bayaz-Ozturk, Richard V. Burkhauser, and Kenneth A. Couch. All rights reserved. Short sections of text, not to exceed two paragraphs, may be quoted without explicit permission provided that full credit, including $(\mathrm{C}$ notice, is given to the source. 
Consolidating the Evidence on Income Mobility in the Western States of Germany and the U.S. from 1984-2006

Gulgun Bayaz-Ozturk, Richard V. Burkhauser, and Kenneth A. Couch

NBER Working Paper No. 18618

December 2012

JEL No. J1,J6

\title{
ABSTRACT
}

The cross-national intragenerational income mobility literature assumes within-country mobility is invariant over the period measured. We argue that a great social transformation-German reunificationabruptly and permanently altered economic mobility. Using standard measures of mobility (with panel data for the western states of Germany and the U.S.) over the entire period 1984-2006, we find the conventional result that income mobility is greater in Germany. But when we cut the data into moving five-year windows and compare mobility before and after reunification, income mobility declines significantly over the years immediately following reunification in Germany but not in the U.S.

\author{
Gulgun Bayaz-Ozturk \\ CUNY School of Public Health \\ 2180 Third Avenue \\ New York, NY 10035 \\ gbayazoz@hunter.cuny.edu \\ Richard V. Burkhauser \\ Cornell University \\ Department of Policy Analysis \& Management \\ 259 MVR Hall \\ Ithaca, NY 14853-4401 \\ and NBER \\ rvb1@cornell.edu
}

Kenneth A. Couch

University of Connecticut

Kenneth.Couch@uconn.edu 


\section{Introduction}

The empirical literature comparing the rate of intragenerational income mobility across countries either implicitly or explicitly assumes it is invariant over the time period measured (See Burkhauser and Couch 2009 for a review of this literature). Here we provide evidence that while it is likely to be so in ordinary times, great social transformations can abruptly alter a country’s rate of income mobility. This paper focuses on one such social transformation, the reunification of Germany, and argues that it is associated with the substantial differences in the measured levels of income mobility in Germany across time periods considered in this literature. We do so by examining the rate of income mobility among a representative panel of residents living in the western states of Germany before and after reunification using data that span a quarter of a century, and contrasting it with a similar representative panel of United States residents over the same time period. We find that income mobility among residents of the western states of Germany during 1984-1988 fell significantly in the years following German reunification, while the income mobility of U.S. residents during this same period either remained constant or rose depending on the measure used. ${ }^{1}$

In our analysis, we make use of data from 1984-2006 in both the western states of Germany and the U.S. Analyses of these data prior to reunification indicated that despite higher cross-sectional income inequality in the U.S., it was characterized by relatively lower income mobility than found in the western states of Germany (Burkhauser and Poupore 1997; Maasoumi and Trede 2001). This finding was surprising since it contrasted sharply with the popular view

\footnotetext{
${ }^{1}$ The process that ended the separation of the residents of the western and eastern states of Germany began in May 1989 with the removal of the Hungarian border barriers and the subsequent flow of eastern residents into the western states. The Berlin Wall fell in early November 1989 and German Chancellor Kohl quickly announced a 10-point plan calling for German reunification. In May 1990 a treaty of monetary, economic and social union was signed, and in July 1990 the Deutsche Mark once again became the common currency for all of Germany.
} 
that while the U.S. has higher levels of cross-sectional income inequality, this is offset by greater income mobility.

In extending this research over longer time spans, it is important to consider whether the most commonly used measures of income mobility converge to a stable rate as more years of data are added to the analysis. The most commonly used measure of economic mobility, the Shorrocks $R$ (Shorrocks 1978), is simply the ratio of permanent to total inequality with higher values signaling a less mobile society. The movement of individuals through an income distribution associated with mobility reduces the extent of permanent inequality. So as years of data are added to the analysis, if the "paths of mobility” are stable, the measure should converge to a constant.

We consider this point using the Shorrocks $R$ as well as a measure employed by Gangl (2005) based on the Gottschalk and Moffitt (1994) method for decomposing the variance in earnings (G-M decomposition). To do so, we use U.S. Panel Study of Income Dynamics and German Socio-Economic Panel income years 1984-2006. Using both measures we find that the rate of long-term income mobility does not converge to a constant over this 23-year time span.

The fact that neither of these income mobility measures asymptote to a constant value suggests that income mobility may be period specific and hence could change appreciably over different calendar time periods if the paths of income mobility change. To test this hypothesis, we divide our single balanced panel into moving five-year balanced panels. Doing so allows us to obtain a clean measure of the rate of income mobility through the five-year window just prior to German reunification (1984-1988) for the population living in the western states of Germany, contrast it with the income mobility of those same individuals observed in all subsequent five- 
year windows including those that begin after reunification, and compare those outcomes with similar measures of income mobility for residents of the U.S. over the same time periods.

Using both measures, we find, as did the original literature, that income mobility among residents of the western states of Germany was higher than among residents of the U.S. just prior to reunification (1984-1988). But we then show that economic mobility fell significantly among the German but not the U.S. population in the years following reunification.

Below we provide a fuller description of the literature that most directly relates to our analysis, the methods we use to estimate income mobility, and the data samples for each country. We then present our empirical results and conclusions.

\section{Literature Review}

Cross-sectional measures of income inequality include both transitory and permanent components. Researchers have long sought to quantify their relative importance. Shorrocks (1978) provides one of the first methods for doing so. We formally define this measure in the methods section, but note here that it conceptualizes immobility as a ratio of inequality over time due to permanent influences to total inequality from all sources over that same period. Using data on residents of the western states of Germany and the U.S. from 1983 to 1988, Burkhauser and Poupore (1997) confirmed that the disposable (post-tax, post-transfer) household sizeadjusted income of Americans was more unequally distributed than was the case in the western states of Germany over the years just prior to reunification. But surprisingly, they also found that immobility based on their Shorrocks $R$ measure was also higher in the U.S.

Maasoumi and Trede (2001) provide an important re-examination of Burkhauser and Poupore (1997). They developed a distributional theory for calculating appropriate standard errors for the Shorrocks $R$ and formally test the significance of observed differences in their 
estimates across residents of the western states of Germany and the U.S. Using the same data and time period, but recasting the Shorrocks $R$ as a measure of mobility $(M=1-R)$, Maasoumi and Trede state (p. 557): “Our main finding is that mobility estimates are statistically significantly higher in Germany than in the United States.”

Several other studies have made use of samples of data for the western states of Germany and the U.S. that span the event of reunification to examine individual mobility in the distribution of household size-adjusted disposable income (Gottschalk and Spolaore 2002; Van Kerm 2004; Jenkins and Van Kerm 2006). Van Kerm (2004) uses the Maasoumi and Trede $M$ measure over the years 1985 to 1997 and also finds that individuals in the U.S. were significantly less mobile than those in the western states of Germany. Gottschalk and Spolaore (2002) and Jenkins and Van Kerm (2006) use alternative measures of mobility but do so with samples beginning before and ending after reunification and also find evidence of greater income mobility in the western states of Germany than the U.S.

Other studies focus on the years since German reunification (Ayala and Sastre 2002; Gangl 2005; Chen 2009) to examine income mobility in the entire country following reunification. Ayala and Sastre (2002, p. 5) make use of data from 1992 to 1997 to examine mobility of individuals in the distribution of household size-adjusted disposable income for the U.S. and reunified Germany along with a number of other countries. One measure they consider, which is similar to the Shorrocks $R$, is the trace of a transition probability matrix they construct for movements across deciles over time. In Table 4 (p. 39), they report higher income mobility in reunified Germany than in the U.S. despite Germany's lower levels of cross-sectional income inequality. These findings suggest that mobility trends for those living in reunified Germany over the 1990s were not much different from those found in the earlier literature focusing on those 
living in the western states of Germany prior to reunification, with both these German population groups experiencing greater income mobility than similarly defined U.S. sample populations over these time periods.

Gangl (2005) also examines the experiences of reunified Germany and the U.S. using data from 1992 through 1999 along with many other countries. He also considers the movement of individuals through the distribution of household size-adjusted disposable income. But based on the Shorrocks $R$ (Table 1, p. 150), he finds that Germany and the U.S. have similar levels of mobility. He concludes that, "Comparing the evidence for the 1990s with Burkhauser and Poupore's (1997) data for the 1980s, it seems that income mobility has increased in the United States but declined sharply in reunified Germany (p.151).”² But he does not compare similar German populations before and after reunification.

Chen (2009) also makes use of panel data from 1991 through 2003 to examine differences in mobility in the U.S., reunited Germany, and other countries. The study also examines the movement of individuals through the household size-adjusted distribution of disposable income. Using the Maasoumi and Trede $M$ measure, the study finds that mobility in the U.S. in the period from 1993-1996 is greater than in reunified Germany. Chen notes (p. 88): "This suggests that income mobility has increased considerably in the United States between the 1980s and 1990s, while it declined in Germany.” But once again this study does not compare similar German populations before and after reunification.

Hence, in samples drawn prior to reunification, there is considerable evidence based on the work of Burkhauser and Poupore (1997) and Maasoumi and Trede (2001) that residents of the western states of Germany lived in a relatively more mobile society characterized by less

\footnotetext{
${ }^{2}$ Gangl also makes use of the ratio of permanent to total variance of log incomes (G-M decomposition) as a measure of permanent income inequality and rigidity as we do in this study. This is explained in detail in the methods section.
} 
cross-sectional and permanent inequality than in the U.S. In samples that span the time of reunification (Gottschalk and Spolaore 2002; Van Kerm 2004; Jenkins and Van Kerm 2006) and focus on residents of the western states of Germany both before and after reunification, consistent evidence continues to emerge that the U.S. is less mobile. However, studies using samples of residents of all the states of Germany following reunification report rates of mobility that are the same or lower than for those residing in the U.S. over this period, although there is some disagreement on this finding (Ayala and Sastre 2002). So, is the apparent inconsistency in the findings of studies focusing on the mobility of those living in the western states of Germany before unification, even when they are followed into the 1990s, and the mobility of all those living in reunified Germany associated with reunification itself?

In our analysis, we focus on residents of the western states of Germany prior to reunification and show that simply extending the years that this population is followed to measure their income mobility results in findings similar to the previous literature even when the observational period is extended to 2006. But when the assumption that measures of intragenerational mobility are invariant over the time period measured is dropped and tested using moving five-year windows that allow us to measure mobility before and after reunification for this population, we find evidence that a great social transformation, in this case German reunification, is coincident with a significant decline in their income mobility. This finding is consistent with post-reunification studies of the entire population of reunited Germany. We then provide some evidence that this significant drop in income mobility in our German population is not the result of more general world economic conditions by comparing income mobility for a similar population—residents of the U.S. in the years 1983-1988. We find no such income 
mobility decline. In doing so, we provide an explanation that consolidates this literature.

\section{Methods}

The relationship between intragenerational economic mobility and the relative magnitudes of permanent and transitory inequality are described in Burkhauser and Couch (2009). Over time, standard measures of permanent income for individuals average or sum multiple observations in order to reduce the contribution of transitory error at any point in time. Thus, a ratio of permanent to total variation in income shows how static individual positions are in the income distribution. Here our main measure of income mobility is the Shorrocks $R$. We also use the GM decomposition measure as a robustness check of our principal findings.

The Shorrocks $R$ defines mobility as the ratio of a multi-year inequality value $I(Y)$ to the weighted average of single-year inequality values $I\left(Y^{t}\right)$ where the weights $\left(w_{t}\right)$ are the ratio of mean income in year $t\left(\mu_{t}\right)$ to the mean income over all $t$ years $(\mu)$.

$$
0 \leq R=\frac{I(Y)}{\sum_{t} w_{t} I\left(Y^{t}\right)} \leq 1
$$

The value of the numerator, which represents permanent inequality, cannot exceed the weighted average of the single year inequalities in the denominator. $R$ can take values between zero and one where zero indicates a completely mobile society and one indicates a completely immobile society. The values between zero and one show the extent to which the income distribution is equalized as the time interval is extended. Since longer time periods accommodate more opportunities for relative income movements and smooth out life cycle effects, $R$ measures the extent to which cross-sectional inequality declines by extending the accounting period. Hence, the $R$ measure reflects the proportional contribution of permanent to total income inequality over time. 
The calculation of the Shorrocks $R$ requires the use of inequality measures that are strictly convex functions. The estimations presented here make use of the Theil index, $I_{1}$, which satisfies the strict convexity property. Moreover, it is additively decomposable, mean independent, and it satisfies the Dalton-Pigou principle of transfers. The Shorrocks $R$ is calculated using the following formula:

$$
I_{1}(Y)=\frac{1}{n} \sum_{i} \frac{Y_{i}}{\mu} \log \frac{Y_{i}}{\mu}
$$

Where: $n$ is the number of individuals, $\mu$ is mean income and $Y_{i}$ is the income of individual $i$. Total income of an individual over $t$ years is obtained by $Y_{i}=\sum_{t} Y_{i}^{t}$. Earlier studies demonstrate the robustness of patterns in cross-national differences using alternative inequality measures (Burkhauser and Poupore 1997; Maasoumi and Trede 2001; Chen 2009). This analysis focuses only on calculations based on the Theil index. ${ }^{3}$

In addition to the Shorrocks $R$, we examine trends in intragenerational mobility using decomposition methods developed by Gottschalk and Moffitt (1994). In our G-M decomposition, permanent income, $\overline{y_{i}}$ is the mean of log income measured over a given calendar window for each person $i$. In other words, it is the average income for each individual over the time frame of the study. Transitory log income for a person in year $t$ is the difference between the person's log income in year $t$ and their permanent income, i.e. $y_{i}-\bar{y}_{l}$. Hence, the transitory component is the deviation of each observation from the individual averages.

$$
\text { Transitory Variance }=\sigma_{T V}^{2}=\frac{1}{N} \sum_{i=1}^{N} \frac{1}{T_{i}-1} \sum_{t=1}^{T}\left(y_{i t}-\bar{y}_{t}\right)^{2} \text {. }
$$

\footnotetext{
${ }^{3}$ The Theil coefficient emphasizes the changes in the middle of the income distribution.
} 


$$
\text { Permanent Variance }=\sigma_{p v}^{2}=\frac{1}{N-1} \sum_{i=1}^{N}\left(\bar{y}_{i}-\overline{\bar{y}}\right)^{2}-\frac{\sigma_{T V}^{2}}{\bar{T}} \text {. }
$$

where: $\overline{\bar{y}}$ is the mean of log income across the whole sample and $\bar{T}$ is the mean years over the individuals in a time window. Using these estimates of transitory and permanent variance, we construct ratios of permanent to total variance to estimate the degree of immobility in the income distribution based on the G-M decomposition measure of mobility. Burkhauser and Couch (2009) discuss the conceptual correspondence between the ratio of permanent to total variance of income based on the G-M decomposition method and the Shorrocks $R$ which is a ratio of permanent to total inequality. Gangl (2005) also makes use of the ratio of permanent to total variance in log incomes as an alternative measure in his comparative study of mobility.

We use the Biewen (2002) method to construct confidence intervals for tests of differences in mobility over time within both our German and U.S. samples. That is, we use the method of bootstrapping to construct confidence intervals where an estimate of the sampling distribution of a mobility index is obtained by re-sampling from the original sample. One advantage of this method is that it takes into account the intertemporal covariance structure of incomes without explicitly dealing with covariance calculations. Hence, this method accounts for the longitudinal correlation in panel data for a country. To obtain more precise estimates, we construct 95 percent confidence intervals of income mobility differences by using Biewen’s bootstrapping scheme. Our estimates are based on 10,000 bootstrap replications.

Maasoumi and Trede (2001) use the delta method and the theory of method of moments to build the asymptotic sampling distribution of our Shorrocks $R$ values estimated here. We use their procedure to calculate standard errors for our t-tests of differences across our point estimates of these values as well as those of our G-M decomposition values, in a given time period, for our German and U.S. samples. 


\section{Data}

We use data from the Cross-National Equivalent File (CNEF), a multi-national longitudinal micro-database distributed by Cornell University. The CNEF supports comparative research by providing comparably defined cross-national variables from the raw data. The CNEF uses the German Socio-economic Panel (GSOEP) and the U.S. Panel Study of Income Dynamics (PSID). We focus on survey years 1985 to 2007 (or income years 1984 through 2006) for both countries, using information from every second year. ${ }^{4}$ We omit alternative years of data from the analysis because the PSID started collecting data biannually in 1997. Consistent data usage over time makes the omission of the alternating years necessary. ${ }^{5}$ Moreover, because of the differences in income inequality in the eastern and western states of Germany and the lack of data coverage for the eastern states of Germany prior to reunification in the GSOEP-CNEF, the analysis is restricted to the western states of Germany (Grabka, Schwarze, and Wagner 1999).

We focus on the disposable (post-tax, post-transfer) size-adjusted household income of individuals. ${ }^{6}$ Disposable income is the sum of labor earnings, asset flows, private and public transfers, the imputed rental value of owner-occupied housing and other income sources of all individuals in a household minus taxes. The TAXSIM programs provide disposable income for the U.S. Disposable income estimates for German households are based on the method developed by Scharwze (1995). The unit of analysis is the person. We assume that disposable income is shared equally within the household and we adjust for differences in household size

\footnotetext{
${ }^{4}$ Kim and Stafford (2000) examine changes in income measures in the PSID over time. Their analysis identifies two regimes of stability for these measures, one prior to 1980 and one afterwards, with a change in the top code on income in the survey. Since this analysis examines income from 1984 onwards, the analysis occurs within one of the periods of stability in measurement in the PSID.

${ }^{5}$ To check the sensitivity of the results to the potential concern of using alternating years, where possible, comparable estimates are calculated using contiguously available years of data. Both trends and estimates based on contiguous and alternate years of data lie close together, indicating this potential problem is unlikely to have had an important influence on the analysis.

${ }^{6}$ The data is adjusted for inflation using CPI indices. Base income year is 1991 for both countries.
} 
using an equivalence scale elasticity of 0.5 . These equalized incomes are assigned to each person in the household.

The analytical assumptions we make here are standard in the cross-national income inequality literature (see Atkinson, Rainwater, and Smeeding 1995) and are similar to those in the other studies of mobility discussed in the review of prior literature. Only survey respondents who live in households with positive income in all relevant years are included in our sample. Samples are appropriately weighted to represent the population and also to take into account the effect of attrition in both surveys. Appendix A contains a more detailed discussion.

Finally to test our main hypothesis that a great social transformation—-the reunification of Germany—can explain the substantial differences in the measured level of income mobility over the years 1984-2006 we create a single balanced panel of those living in the western states of Germany in 1984-1988 as well as in all subsequent five-year time windows through 2002-2006. We then compare our results with results based on a similar balanced panel of those living in the United States over this same time period. We also explored alternative methods of arranging our data. For example, we dropped our single balanced-panel design and compared five-year windows that only require individuals to have positive income values over that five-year window rather than over the entire period from 1984-2006 with virtually identical results.

\section{Results}

Table 1 shows yearly cross-sectional income inequality levels for our samples of persons living in households with positive disposable income over the period 1984 to 2006 in the western states

of Germany and the U.S. based on a Theil $I_{1}(Y)$ income inequality measure. Standard errors are in parentheses.

\section{*** [Insert Table 1 Approximately Here] $* * *$}


Income inequality increases in both our German and U.S. samples between 1984 and 2006 but is always higher in the U.S. The final row in Table 1 shows the Shorrocks $R$ values for the period beginning in 1984 and ending in 2006. Over this 23-year period (using data for all even years), the value of the Shorrocks $R$ for income is 0.645 in the western states of Germany and 0.673 in the U.S. Assuming that these two country samples are independent, income mobility is significantly higher for residents of the western states of Germany than for similar residents in the U.S. population. This finding is consistent with all previous studies focusing on these pre-reunification populations.

The Shorrocks $R$ values for our German and U.S. samples in Table 1 were computed over the 23-year window from 1984-2006 using the 12 years of data described in that table. Figure 1 contains Shorrocks $R$ values estimated sequentially for all possible time windows. The resulting stability curves show the influence of including additional years of data on the updated estimates of the Shorrocks $R$ value. By definition, $R$ is equal to 1 when the accounting period is composed of one year. For any successive combination of years beginning with 1984 through 2006, our German sample has a lower $R$ value than is the case for the U.S.

\section{*** [Insert Figure 1 Approximately Here] ${ }^{* * *}$}

This pattern is consistent with Germany having a more mobile structure of disposable income than the U.S. Assuming that the samples of the two countries are independent, the $R$ measures are statistically significantly different for all time horizons. For example, the value of $R$ that spans the period of 1984-1988, the five-year period just prior to reunification, is 0.788 for the residents of the western states of Germany and 0.869 for U.S. residents. Incorporating all years of data, the Shorrocks $R$ values decline to 0.645 and 0.673 respectively, the values reported in the last row of Table 1 . The immobility curves keep declining as the accounting period is 
extended and additional years of data are added to the calculation of the Shorrocks $R$. However, there is a slowdown in the pace of the decline beyond the early 1990s for both residents of the western states of Germany and the U.S.

We repeat our construction of these immobility curves using G-M decomposition values and also plot them in Figure 1. Because the G-M decomposition values require two data points to calculate, our first value is for 1986. The G-M decomposition values for the western states of Germany are consistently below the U.S. values for all time periods and decline continuously between 1986 and 2006. Researchers using either of these methods would draw the conclusion that while the level of immobility falls in both samples as additional years are added to the panels beginning at the point where they were comparable (1984 income year), residents of the U.S. are consistently found to live in a less mobile society than residents of the western states of Germany. However they would also conclude that contrary to expectations, these measures of immobility do not appear to asymptote to a stable value.

Researchers using different panel data sets may not always be able to temporally align the data from different countries as we have done here. However, the underlying mathematics used in developing the Shorrocks $R$ and the G-M decomposition values suggest that with a sufficiently long collection of panel data, their values should converge to a constant. If this convergence occurred quickly in different panel data sets, as some have suggested might be the case for the U.S. (see Gittleman and Joyce 1999), researchers might be able to conduct analyses of mobility making use of panel data sets that start in different calendar years. The long-run immobility measures in each individual country would converge to the same constant regardless of the starting point of the analysis. But in Figure 1, using data that span 23 years, we find that neither the Shorrocks $R$ nor the G-M decomposition values appear to quickly asymptote to a constant. 
The fact that neither of these income mobility measures quickly asymptote to a constant value suggests that income mobility may be period-specific and hence could change appreciably over different calendar time periods if the paths of income mobility change. We now investigate this possibility of a change in the path of mobility by explicitly testing whether or not the rate of intragenerational income mobility is always invariant over the time period measured by focusing on one such potential "path of mobility" changing event, the reunification of Germany, and argue that it may explain the substantial differences in the measured levels of income mobility in

Germany and the U.S. across time periods considered in this literature.

To test this hypothesis, we divide our single panel into moving five-year windows of the same individuals and estimate Shorrocks $R$ and G-M decomposition values for each panel. Doing so allows us to observe a clean measure of the rate of income mobility through the fiveyear time window just prior to reunification (1984-1988) of the population living in the western states of Germany, contrast it with the income mobility of those same individuals observed in all subsequent five-year intervals including those that begin after reunification, and compare those outcomes with similar measures of income mobility for residents of the U.S. over the same time periods. ${ }^{7}$

Figure 2 contains the Shorrocks $R$ values for our German population. Over the 10 fiveyear windows of data that span calendar years 1984-2006, German income immobility rises from 0.788 for the post-reunification period $1984-1988$ to 0.829 for the first full post-reunification period 1992-1996, as post-reunification years replace pre-reunification years in our five-year

\footnotetext{
${ }^{7}$ In an appendix available on request, we provide a collection of Shorrocks $R$ and G-M decomposition values for the U.S. and the western states of Germany similar to those contained in Figure 1. These series are based on 11 samples for each country that employ different initial years. In principle we could have used any of these time windows that vary in length from two to 23 years in our analysis. We chose a five-year window here because it best allows us to examine pre- and post-reunification periods for Germany.
} 
windows. Thereafter, our Shorrocks $R$ values are relatively stable. In 2002-2006, the last fiveyear window of our data, the $R$ value of .848 .

*** [Insert Figure 2 Approximately Here] ***

Figure 2 also contains the G-M decomposition values for these same five-year windows. ${ }^{8}$

Again, we observe a substantial rise in German immobility from 0.562 in our five-year pre-

reunification period 1984-1988 to 0.689 in 1992-1996, as post-reunification years replace pre-

reunification years in our five-year windows. Mobility values vary more over the remaining

windows than is the case with the Shorrocks $R$ values but never return to 1984-1988 levels and

reach a value of 0.719 during 2002-2006. ${ }^{9}$

To determine the statistical significance of the marked increase in income immobility in

this population before and after German reunification, we bootstrapped confidence intervals for

pair-wise differences in Shorrocks $R$ values for our clean pre-reunification five-year window

(1984-1988) and all other five-year windows based on the method developed by Biewen (2002).

As can be seen in column 1 of Table 2, as soon as post-reunification years replace pre-

reunification years in 1986-1990, the increase in the Shorrocks R observed in Figure 2 is

significant at the 95 percent level—significance at this level is obtained when the confidence

\footnotetext{
${ }^{8}$ Gottschalk and Moffitt (2009) provide estimates of transitory variance in the disposable household size-adjusted income of persons. However, they do not provide estimates of permanent variance which would allow us to directly compare their estimates to ours. We have compared the component of transitory variance used in our calculations with their work and observe similar trends.

${ }^{9}$ Bartels and Bonke (2010) capture, in five-year windows starting in 1984, the earnings volatility of prime-age men (aged 20-59) who live in the western states of Germany, using an alternative formulation of Gottschalk and Moffitt (1994) methods. They also look at the household size-adjusted disposable income of this subsample of the population. They find a sustainable increase in earnings volatility over these windows but little difference in income volatility. Since they exclude persons living in households without males aged 20-59, their finding cannot be directly related to the traditional income mobility literature discussed here which focus on the entire population. In addition, they create new populations in each of their five-year windows rather than follow the same population over all years. In contrast, Biewen (2005), who does focus on the entire population of the western states of Germany using Gottschalk and Moffitt methods, depending on his measure, finds either constant or declining household sizeadjusted disposable income mobility for residents of the western states of Germany from 1990-1998.
} 
intervals do not span the value zero-and remains so over all subsequent five-year windows, thus confirming that the immobility in Germany has increased in the post-reunification years.

\section{*** [Insert Table 2 Approximately Here] ${ }^{* * *}$}

In column 2 of Table 2 we repeat this exercise for our German G-M decomposition values . Again, these calculations are performed using Biewen's method. As post-reunification years replace pre-reunification years, the increases in the G-M decomposition values observed in Figure 2 for the western states of Germany become closer to being significant at the 95-percent level. German immobility is significantly higher in 1988-1992 than measured in 1984-1988 and remains so over all subsequent five-year windows, reinforcing our Shorrocks $R$ findings that immobility among residents of the western states of Germany significantly increased at the time of reunification.

Hence when we cut our data into five-year windows and compare mobility before and after reunification for residents of the western states of Germany, we find income mobility is significantly lower in Germany than in the years (1984-1988) prior to reunification using either measure. But is this simply the result of general world conditions before 1989 and after 1990 or can this significant change in mobility be attributed to German reunification? While this is far from a strict difference-in-difference analysis, in Figure 2 and Table 2 (columns 3 and 4), we compare our outcomes in our German population with residents of the U.S. over the same time periods to look for common patterns.

Figure 2 also contains the Shorrocks $R$ values for our U.S. population. In contrast to our German sample, U.S. income immobility fell from 0.869 for the pre-reunification period 1984- 
1988 to 0.823 for the first full post-reunification period 1992-1996. As in our German sample, immobility remained relatively constant over the rest the period.

Figure 2 also contains the G-M decomposition values for these same five-year windows. ${ }^{10}$ Again, we observe in contrast to our German sample, a substantial fall in U.S. immobility from 0.718 in our five-year pre-reunification period 1984-1988 to 0.613 in 19921996, as post-reunification years replace pre-reunification years in our five-year windows. As with our German sample, mobility values vary more over the remaining windows than is the case with our Shorrocks $R$ values. In this case however they continue to fall through 1994-1998 before rising in subsequent windows, but never return to 1984-1988 levels.

Again, we conduct tests of the differences in measures of mobility in the U.S. in the first five-year window relative to later periods. Columns 3 and 4 of Table 2 verify that, unlike in Germany, income mobility in the U.S. rose from 1984-1988 levels and was significantly higher by 1990-1994 based on both the Shorrocks $R$ measure and the G-M decomposition value. ${ }^{11}$ It remained significantly higher in all subsequent years using the G-M decomposition measure and in all years except 2004-2006 using the Shorrocks measure.

As a result of these different patterns of movement across the 10 five-year windows we find, consistent with Maasoumi and Trede (2001), when we use their methodology to calculate standard errors for each Shorrocks $R$ value, that mobility among residents of the western states of Germany was significantly greater in pre-reunification years 1984-1988 than in the U.S. But

\footnotetext{
${ }^{10}$ Gottschalk and Moffitt (2009) provide estimates of transitory variance for the disposable household size-adjusted income of persons. However, they do not provide estimates of permanent variance which would allow us to directly compare their estimates to ours. We have compared the component of transitory variance used in our calculations with their work and observe similar trends.

${ }^{11}$ In order to explore the differences in mobility patterns over longer time spans, we also constructed confidence intervals which cover an 11-year time span. We observe that the value zero is contained in all 95-percent intervals for the United States which implies that the differences in the pairs of mobility measures are not statistically significant. This result is consistent with the finding of Gittleman and Joyce (1999). They also do not find any apparent trend in mobility measures with a 10-year time span. However, our results using these extended time periods in Germany are consistent with those of five-year time periods.
} 
when these same residents are compared in subsequent years, there typically is no significant difference in the $R$ values except in 2000-2004 where the U.S. has greater mobility. The estimates and standard errors that support these comparisons are contained in Appendix B Table B.1. Making similar comparisons using standard errors calculated for our individual G-M decomposition values (Appendix B Table B.2) we also find that mobility in 1984-1998 is significantly higher in our German sample than in our U.S. sample. But there is no significant difference in mobility between the two samples in the post-reunification period.

\section{Conclusions}

The empirical literature comparing intragenerational income mobility across countries assumes within-country mobility is invariant over the period measured. When we make this same assumption and use the two most common classes of income mobility measurement (Shorrocks $R$ and the Gottschalk and Moffitt Decomposition) with panel data on residents of the western states of Germany and the U.S. over the entire period 1984-2006, we find the conventional result found by others who have tracked these populations over shorter periods since 1984. Income mobility declines steadily in both populations as additional years of information are added to our calculation. But income mobility is significantly greater in Germany than the U.S in all periods. Hence our research is consistent with past research using this method of estimating income mobility. However, even after nearly a quarter of a century (1983-2006), income mobility does not appear to asymptote to a stable value in either country.

This suggests that either period effects are delaying this movement to a stable outcome in both populations or are so important that rather than simply delaying movement to a stable value, they have significantly changed the underlying path of mobility in a country. We provide evidence that such an exogenous shock initiating a "great social transformation" occurred for 
residents of the western states of Germany in 1989-1990, significantly altering their income mobility — the reunification of Germany.

When we test for this possibility by cutting our data into five-year windows and comparing mobility within our before- and after-reunification windows on the population of residents of the western states of Germany in 1984-1988, we find income mobility is significantly lower in our post-reunification five-year windows than in the pre-reunification window (1984-1988) using both the Shorrocks $R$ and G-M decomposition measures. In contrast when we do the same with the U.S. sample, we find no significant decline in mobility. Such a German-specific shock is consistent with the substantial differences in the measured levels of income mobility in Germany using standard (Shorrocks $R$ or G-M decomposition) methods on this pre-reunification sample of residents of the western states of Germany up to present times, and with those studies using these same methods, but on the residents of both the western and eastern states of Germany beginning post-reunification.

It is also consistent with the differences in mobility found in the cross-national comparative literature for Germany and the U.S. We find income mobility is significantly greater in Germany than in the U.S. in the five-year window (1984-1988) prior to reunification. But when we look at these same populations in subsequent windows as post-reunification years replace pre-unification years, there is no significant difference in their mobility rates using either of our measures of mobility. In fact, using the Shorrocks $R$ measure, we find in one recent fiveyear period in our data (2000-2004), income mobility is significantly lower in Germany than in the U.S. population.

It is beyond the scope of this paper to determine the specific sources of the change in income mobility among our German population that accounts for the significant decline in 
mobility in post-reunification Germany. However, when we use our same methods and focus on the mobility of prime-age men (aged 25-59) in Germany and the U.S., we find that earnings mobility in this population follows patterns similar to those for income mobility. 


\section{References}

Atkinson, A. B., L. Rainwater, and T. Smeeding. "Income Distribution in OECD Countries: Evidence from the Luxembourg Income Study.” Social Policy Studies No. 18. Paris:

Organization for Economic Cooperation and Development, 1995.

Ayala, L., and M. Sastre. "Europe versus the United States: Is there a Trade-off between Mobility and Inequality?” Working Paper 19/2002, European Economy Group, 2002.

Bartels, C., and T. Bonke. "German Male Income Volatility 1984 to 2008: Trends in Permanent and Transitory Income Components and the Role of the Welfare State.” Deutsches Institut fur Wirtschaftsforschung, Berlin, SOEP papers on Multidisciplinary Panel Data Research, No. 325, 2010.

Biewen, M. "The Covariance Structure of East and West German Incomes and Its Implications for the Persistence of Poverty and Inequality.” German Economic Review, 6(4), 2005, 445-69.

Biewen, M. “Bootstrap Inference for Inequality, Mobility and Poverty Measurement.” Journal of Econometrics, 108, 2002, 317-42.

Burkhauser, R. V., and K. A. Couch. “Cross-sectional and Intra-generational Mobility,” in The Oxford Handbook of Economic Inequality, edited by W. Salverda, B. Nolan, and T. Smeeding. New York: Oxford University Press, 2009, 522-48.

Burkhauser, R. V., and J. G. Poupore. "A Cross-national Comparison of Permanent Inequality in the United States and Germany.” Review of Economics and Statistics, 79, 1997, 10-17.

Chen, W. H. “Cross-national Differences in Income Mobility: Evidence from Canada, the United States, Great Britain and Germany.” The Review of Income and Wealth, 55(1), 2009, 75-100.

Gangl, M. “Income Inequality, Permanent Incomes, and Income Dynamics.” Work and Occupations, 32(2), 2005, 140-62.

Gittleman, J., and M. Joyce. “Have Family Income Mobility Patterns Changed?” Demography, 36(3), 1999, 299-314.

Gottschalk, P., and R. Moffitt. "The Growth of Earnings Instability in the United States.” Brookings Papers on Economic Activity, 2, 1994.

Gottschalk, P., and R. Moffitt. “The Rising Instability of U.S. Earnings.” Journal of Economic Perspectives, 23(4), 2009, 3-24.

Gottschalk, P., and E. Spolaore. "On the Evaluation of Economic Mobility.” Review of Economic Studies, 69(1), 2002, 191-208. 
Grabka, M. M., J. Schwarze, and G. G. Wagner. "How Unification and Immigration Affected the German Income Distribution.” European Economic Review, 43, 1999, 867-78.

Jenkins, S. P., and P. Van Kerm. “Trends in Income Inequality, Pro-Poor Income Growth, and Income Mobility.” Oxford Economic Papers, 58, 2006, 531-48.

Kim, Y.S., and F. Stafford. "The Quality of PSID Income Data in the 1990s and Beyond.” Survey Research Center, University of Michigan, Ann Arbor, MI, 2000.

http://psidonline.isr.umich.edu/Publications/Papers/tsp/2000-03_Quality_of_PSID_ Income_Data_1990s_Beyond.pdf

Maasoumi, E., and M. Trede. "Comparing Income Mobility in Germany and the United States Using Generalized Entropy Mobility Measures.” The Review of Economics and Statistics, 83, 2001, 551-59.

Schwarze, J. "Simulating German Income and Social Security Tax Payments Using the GSOEP.” Aging Studies Program Paper Series, Maxwell Center for Demography and Economics of Aging, Center for Policy Research, Syracuse University, 19, 1995.

Shorrocks, A. F. "Income Inequality and Income Mobility.” Journal of Economic Theory, 19, 1978, 376-93.

Van Kerm, P. "What Lies Behind Income Mobility? Reranking and Distributional Change in Belgium, Western Germany, and the USA.” Economica, 71, 2004, 223-39. 
Table 1. Cross-sectional Theil measures of income inequality

\begin{tabular}{|c|c|c|}
\hline Year & $\begin{array}{l}\text { Western States } \\
\text { of Germany }\end{array}$ & United States \\
\hline & Disposable Income & Disposable Income \\
\hline 1984 & $\begin{array}{c}0.093 \\
(0.005)\end{array}$ & $\begin{array}{c}0.197 \\
(0.018)\end{array}$ \\
\hline 1986 & $\begin{array}{c}0.085 \\
(0.004)\end{array}$ & $\begin{array}{c}0.192 \\
(0.011)\end{array}$ \\
\hline 1988 & $\begin{array}{c}0.096 \\
(0.005)\end{array}$ & $\begin{array}{c}0.281 \\
(0.032)\end{array}$ \\
\hline 1990 & $\begin{array}{c}0.106 \\
(0.007)\end{array}$ & $\begin{array}{c}0.206 \\
(0.010)\end{array}$ \\
\hline 1992 & $\begin{array}{c}0.107 \\
(0.005)\end{array}$ & $\begin{array}{c}0.211 \\
(0.011)\end{array}$ \\
\hline 1994 & $\begin{array}{c}0.108 \\
(0.005)\end{array}$ & $\begin{array}{c}0.255 \\
(0.018) \\
\end{array}$ \\
\hline 1996 & $\begin{array}{c}0.106 \\
(0.004)\end{array}$ & $\begin{array}{c}0.216 \\
(0.010)\end{array}$ \\
\hline 1998 & $\begin{array}{c}0.125 \\
(0.006)\end{array}$ & $\begin{array}{c}0.352 \\
(0.079)\end{array}$ \\
\hline 2000 & $\begin{array}{c}0.122 \\
(0.009) \\
\end{array}$ & $\begin{array}{c}0.277 \\
(0.018) \\
\end{array}$ \\
\hline 2002 & $\begin{array}{c}0.138 \\
(0.008)\end{array}$ & $\begin{array}{c}0.278 \\
(0.035)\end{array}$ \\
\hline 2004 & $\begin{array}{c}0.126 \\
(0.006) \\
\end{array}$ & $\begin{array}{c}0.385 \\
(0.082) \\
\end{array}$ \\
\hline 2006 & $\begin{array}{c}0.152 \\
(0.011)\end{array}$ & $\begin{array}{c}0.380 \\
(0.023)\end{array}$ \\
\hline$R$ 1984-2006 & $\begin{array}{c}0.645 \\
(0.007)\end{array}$ & $\begin{array}{c}0.673 \\
(0.008)\end{array}$ \\
\hline
\end{tabular}

Note: Standard errors are in parenthesis. See Appendix A for additional details. 
Figure 1. Immobility in disposable income, Shorrocks $R$ and G-M decomposition, 19842006 (no change in structure)

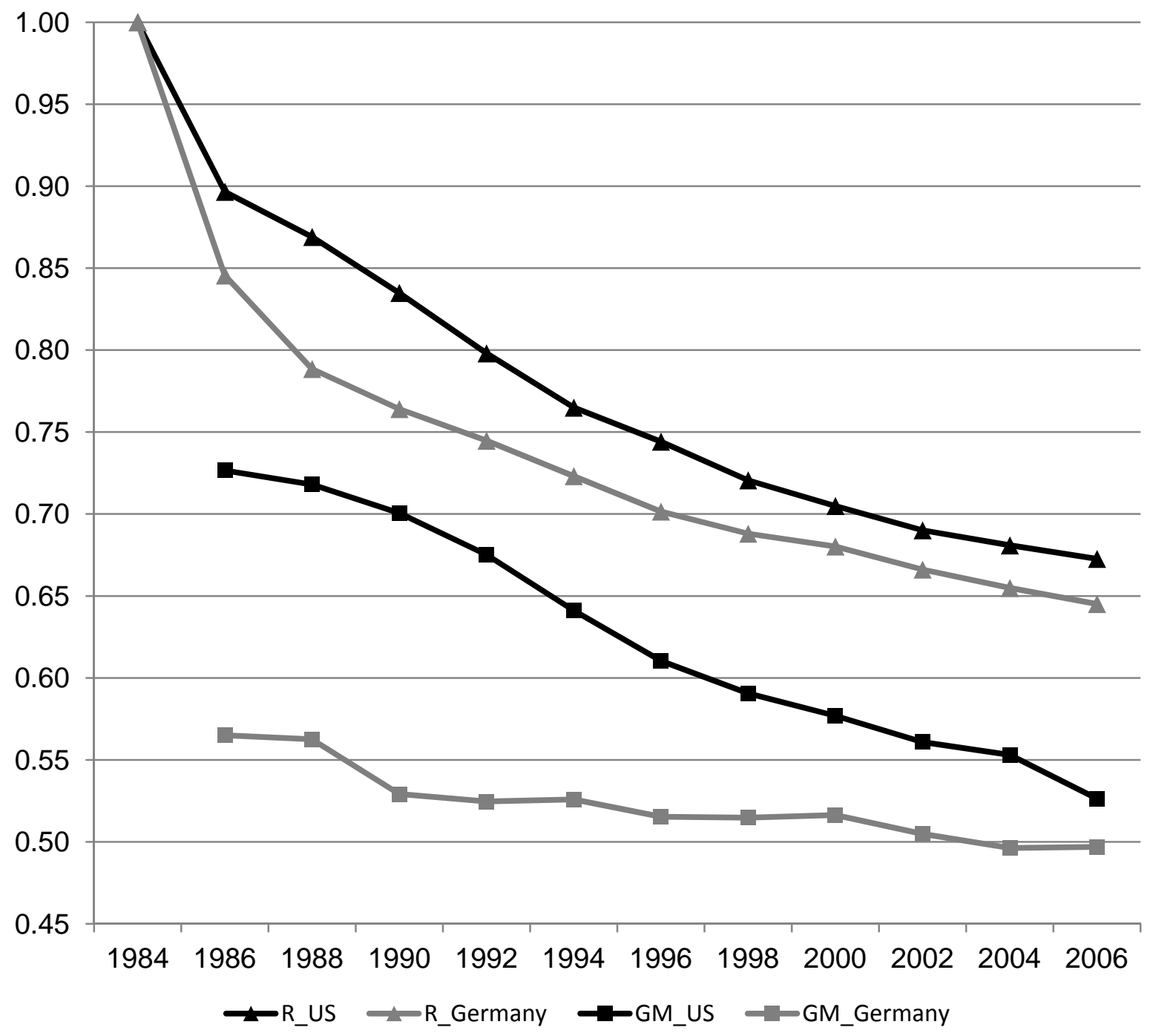


Figure 2. Immobility in disposable income, Shorrocks $R$ and G-M decomposition, 19842006 five-year windows (allowing structure change)

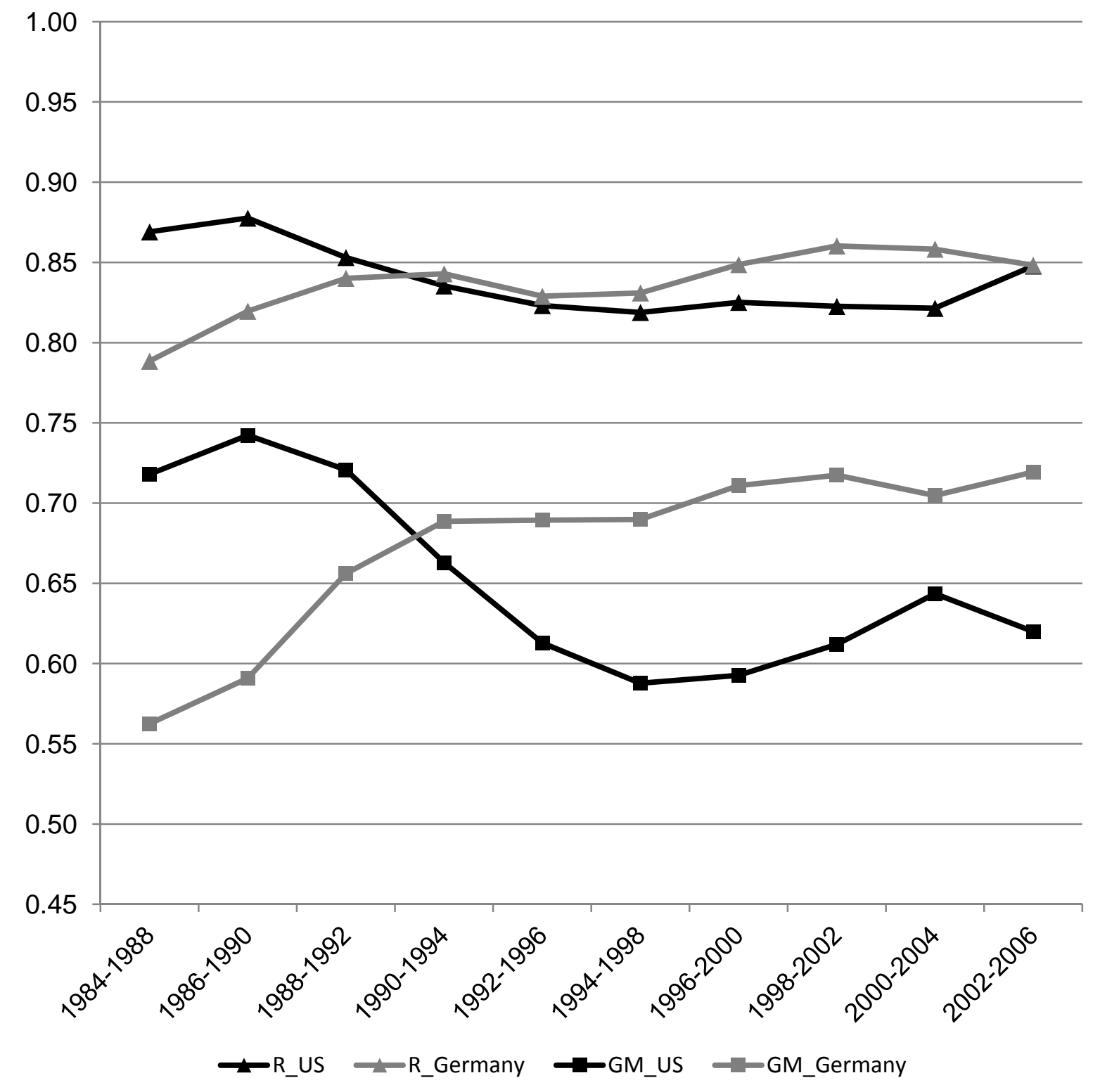


Table 2. Shorrocks $R$ and G-M decomposition, 95-percent confidence intervals

(reference year 1984-1988)

\begin{tabular}{|c|c|c|c|c|}
\hline \multirow[t]{2}{*}{ Year } & \multicolumn{2}{|c|}{ Western States of Germany } & \multicolumn{2}{|c|}{ United States } \\
\hline & Shorrocks $R$ & G-M decomposition & Shorrocks $R$ & G-M decomposition \\
\hline $1986-1990$ & {$[-0.046096 ;-0.016033]$} & {$[-0.097790 ; 0.034856]$} & {$[-0.028378 ; 0.012290]$} & {$[-0.046930 ;-0.001025]$} \\
\hline 1988-1992 & {$[-0.073273 ;-0.029614]$} & {$[-0.172422 ;-0.025743]$} & {$[-0.009632 ; 0.043549]$} & {$[-0.032485 ; 0.026193]$} \\
\hline 1990-1994 & {$[-0.080154 ;-0.029139]$} & {$[-0.206108 ;-0.052753]$} & [0.006798;0.061249] & [0.020049; 0.090177] \\
\hline 1992-1996 & {$[-0.072208 ;-0.011600]$} & {$[-0.199554 ;-0.060631]$} & [0.019995;0.074856] & [0.056201; 0.151977] \\
\hline 1994-1998 & {$[-0.067778 ;-0.016703]$} & {$[-0.190024 ;-0.068097]$} & {$[0.021178 ; 0.083148]$} & [0.081435;0.177939] \\
\hline $1996-2000$ & {$[-0.088034 ;-0.033380]$} & {$[-0.212760 ;-0.089120]$} & {$[0.020174 ; 0.072650]$} & [0.079334; 0.170199$]$ \\
\hline 1998-2002 & {$[-0.104548 ;-0.040781]$} & {$[-0.218759 ;-0.092856]$} & {$[0.015816 ; 0.080433]$} & {$[0.072808 ; 0.139999]$} \\
\hline 2000-2004 & {$[-0.097190 ;-0.041934]$} & {$[-0.216187 ;-0.071412]$} & {$[0.017605 ; 0.080260]$} & {$[0.038972 ; 0.108356]$} \\
\hline 2002-2006 & {$[-0.090123 ;-0.030157]$} & {$[-0.227182 ;-0.089457]$} & {$[-0.007028 ; 0.051846]$} & {$[0.062813 ; 0.133578]$} \\
\hline
\end{tabular}

Notes: Confidence intervals are based on differences between G-M decomposition values for 1985-1989 and relevant other 5year period. 


\section{Appendix A}

We use data from the Cross-National Equivalent Files (2010 release). Cross-sectional estimates in Table 1 are based on our balanced panel of those living in households with positive income in the western states of Germany and in the U.S. over the entire period of 1984 to 2006.

Total household income is equivalence-scale adjusted using the following formula:

$$
E I=\frac{D}{H^{0.5}}
$$

where: $E I$ is equivalent income, $D$ is total disposable household income, $H$ is the household size and 0.5 is the elasticity of scale with respect to household size.

Our measure of economic well-being is disposable (post-tax, post-transfer) household income. In the CNEF, there are two measures of U.S. household disposable income. Their only difference is in how household taxes are estimated. (I11102XX) uses PSID-generated household tax payments while (I11113XX) uses the NBER TAXSIM model to estimate household taxes. Since PSID-generated household tax payments are not available after income year 1990, we use I1113XX. The tax burdens include federal and state income taxes as well as federal payroll taxes.

Household disposable income is the sum of labor earnings, asset flows, private and public transfers, the imputed rental value of owner occupied housing and other income sources of all individuals in a household minus taxes.

Labor earnings in both countries include: wages and salary from all employment (including self-employment income), as well as irregular payments such as: bonuses, holiday pay, and in Germany $13^{\text {th }}$ and $14^{\text {th }}$ month pay.

Asset flows in both countries include: income from interest, dividends and rent.

Private transfers in both countries include: child support, alimony, and income from nonhousehold members.

Public transfers in the U.S. include: AFDC payments, supplemental security income, unemployment compensation, worker's compensation and the face value of food stamps.

Public transfers in Germany include: housing allowances, child benefits, subsistence assistance and special circumstances benefits from the Social Welfare Authority, government student assistance, maternity benefits, unemployment benefits and assistance and unemployment subsistence allowance.

Private pensions in the U.S. include: retirement income from private pension plans, Veterans Administration pensions, and annuities.

Private pensions in Germany include: retirement income from private pension and annuities.

Social security pensions in the U.S. include: social security payments received by the head, partner and other family members.

Social security pensions in Germany include: payments from old age, disability and widowhood pension plans.

The data is adjusted for inflation using CPI indices with a base year of 1991 for both countries. 


\section{Appendix B}

Tables B.1 and B.2 provide five-year estimates for Shorrocks $R$ and G-M decomposition values ratio for both countries.

Table B.1. Shorrocks $R$ Values

\begin{tabular}{lll}
\hline Period & United States & $\begin{array}{l}\text { Western States } \\
\text { of Germany }\end{array}$ \\
$1984-1988$ & $0.869(0.01)$ & $0.788(0.01)$ \\
$1986-1990$ & $0.878(0.01)$ & $0.820(0.01)$ \\
$1988-1992$ & $0.853(0.01)$ & $0.840(0.01)$ \\
$1990-1994$ & $0.835(0.01)$ & $0.843(0.01)$ \\
$1992-1996$ & $0.823(0.01)$ & $0.829(0.01)$ \\
$1994-1998$ & $0.819(0.01)$ & $0.831(0.01)$ \\
$1996-2000$ & $0.825(0.01)$ & $0.849(0.01)$ \\
$1998-2002$ & $0.823(0.01)$ & $0.860(0.01)$ \\
$2000-2004$ & $0.821(0.01)$ & $0.858(0.01)$ \\
$2002-2006$ & $0.848(0.01)$ & $0.848(0.01)$ \\
& &
\end{tabular}

Notes: Standard errors are in parenthesis.

Table B.2. G-M decomposition values

\begin{tabular}{lll}
\hline Period & United States & $\begin{array}{l}\text { Western States } \\
\text { of Germany }\end{array}$ \\
$1984-1988$ & $0.718(0.01)$ & $0.562(0.08)$ \\
$1986-1990$ & $0.742(0.01)$ & $0.591(0.07)$ \\
$1988-1992$ & $0.721(0.01)$ & $0.656(0.07)$ \\
$1990-1994$ & $0.663(0.01)$ & $0.689(0.07)$ \\
$1992-1996$ & $0.613(0.03)$ & $0.689(0.06)$ \\
$1994-1998$ & $0.588(0.03)$ & $0.690(0.06)$ \\
$1996-2000$ & $0.593(0.03)$ & $0.711(0.06)$ \\
$1998-2002$ & $0.612(0.02)$ & $0.717(0.06)$ \\
$2000-2004$ & $0.643(0.02)$ & $0.705(0.05)$ \\
$2002-2006$ & $0.620(0.03)$ & $0.719(0.05)$ \\
& &
\end{tabular}

Notes: Standard errors are in parenthesis. 